Article

\title{
In Situ Synthesis of Bimetallic Hybrid Nanocatalysts on a Paper-Structured Matrix for Catalytic Applications
}

\author{
Hirotaka Koga $^{1, *}$, Yuuka Umemura ${ }^{2}$ and Takuya Kitaoka ${ }^{2,3}$
}

1 Department of Biomaterials Sciences, Graduate School of Agricultural and Life Sciences, The University of Tokyo, 1-1-1 Yayoi, Bunkyo-ku, Tokyo 113-8657, Japan

2 Department of Agro-Environmental Sciences, Graduate School of Bioresource and Bioenvironmental Sciences, Kyushu University, 6-10-1 Hakozaki, Higashi-ku, Fukuoka 812-8581, Japan; E-Mails: azurer@agr.kyushu-u.ac.jp (Y.U.); tkitaoka@agr.kyushu-u.ac.jp (T.K.)

3 Biotron Application Center, Kyushu University, 6-10-1 Hakozaki, Higashi-ku, Fukuoka 812-8581, Japan

* Author to whom correspondence should be addressed; E-Mail: ahkoga@mail.ecc.u-tokyo.ac.jp; Tel./Fax: +81-3-5841-5271.

Received: 25 September 2011; in revised form: 14 November 2011 / Accepted: 18 November 2011 / Published: 25 November 2011

\begin{abstract}
Bimetallic nanoparticles have attracted significant attention as their electrochemical and catalytic properties being superior to those of the individual component nanoparticles. In this study, gold-silver hybrid nanoparticles (AuAgNPs) with an $\mathrm{Au}_{\text {core }}-\mathrm{Ag}_{\text {shell }}$ nanostructure were successfully synthesized on zinc oxide ( $\left.\mathrm{ZnO}\right)$ whiskers. The as-prepared nanocatalyst, denoted AuAgNPs ${ }^{\circledR} \mathrm{ZnO}$ whisker, exhibits an excellent catalytic efficiency in the aqueous reduction of 4-nitrophenol to 4-aminophenol; the turnover frequency was up to 40 times higher than that of each component nanoparticle. Their unique features were attributed to the electronic ligand effect at the bimetallic interface. In addition, the AuAgNPs were synthesized on a $\mathrm{ZnO}$ whisker-containing paper with a fiber-network microstructure, which was prepared via a papermaking technique. The paper-structured AuAgNPs composite possessed both a paper-like practical utility and a good catalytic performance. Furthermore, the on-paper synthesis process for these bimetallic nanocatalysts is facile. These easy-to-handle nanocatalyst hybrid composites are expected to find a wide range of applications in various chemical and catalytic processes.
\end{abstract}

Keywords: gold; silver; bimetallic nanoparticles; zinc oxide whisker; paper-structured catalyst 


\section{Introduction}

Metal catalysts play a key role in a wide range of chemical industries, since they enable the environmentally friendly conversion of various chemical substances. The recent escalation of energy, environmental and resource issues has led to the ever increasing importance of catalytic processes. Thus, extensive efforts have been devoted to the development of high-performance catalytic materials that can promote desired reactions more effectively and selectively [1-3]. In particular, nano-sized metal particles attract increasing attention as highly active heterogeneous catalysts, due to their unique electronic properties and extremely large specific surface areas [4,5]. For example, gold nanoparticles (AuNPs) exhibit good catalytic activities in various chemical reactions [6-12], such as the reduction of 4-nitrophenol (4-NP) to 4-aminophenol (4-AP), which is a useful intermediate for the production of analgesic and antipyretic drugs, in the liquid phase [10], and the low-temperature oxidation of carbon monoxide (CO) in the gas phase [11], even though ordinary bulk Au is known to be an inefficient catalyst $[13,14]$.

In recent years, there has been a growing interest in bimetallic hybrid NPs, since their chemical and physical properties are different from those for both the bulk metals and their monometallic NP counterparts [15-20]. Toshima et al. have reported that core-shell bimetallic NPs exhibit a higher catalytic activity than the monometallic counterparts because the catalytic activity of the shell atoms can be electronically influenced by the core atoms [21-25]. A variety of techniques to tailor bimetallic nanostructures have been investigated, including simultaneous or successive chemical reductions of two types of metal ion [22,26]; it has been reported that platinum $(\mathrm{Pt})_{\text {core }}$ bimetallic $\mathrm{Pt} / \mathrm{Au}_{\text {shell }} \mathrm{NPs}$ were successfully prepared via the multi-step reduction of $\mathrm{HAuCl}_{4}$ and $\mathrm{H}_{2} \mathrm{PtCl}_{6}$ [27]. However, the practical implementation of such metal nanomaterials is challenging, since they are hard to handle. Furthermore, they readily aggregate, resulting in a reduction in surface area and the formation of ordinary bulk metals. This consequently deteriorates their excellent functionality. Thus, the challenge is to establish an efficient and practical immobilization technique that enables highly active metal nanomaterials to be supported onto easy-to-handle matrices.

In our previous reports, the facile and direct in situ synthesis of metal NPs, such as copper $(\mathrm{Cu})$ NPs [28-30], silver (Ag) NPs [31,32], PtNPs [29,30,33] and AuNPs [30,34,35], has been achieved using an easy-to-handle paper matrix, composed of ceramic fibers as the main framework and zinc oxide $(\mathrm{ZnO})$ whiskers as a selective scaffold for the synthesis of metal NPs. For example, the “on-paper" synthesis of AuNPs was successfully achieved as follows [30,34,35]: Firstly, ZnO whiskers are incorporated into a ceramic paper matrix using our established papermaking technique. The $\mathrm{ZnO}$ whisker-containing paper composite ( $\mathrm{ZnO}$ paper) is then simply immersed in an aqueous solution of $\mathrm{HAuCl}_{4}$, leading to the selective formation of AuNPs on the $\mathrm{ZnO}$ whiskers. The as-prepared paper composite, denoted as $\mathrm{AuNPs}^{\circledR} \mathrm{ZnO}$ paper, is like a flexible and easy-to-handle cardboard, and possesses a porous fiber-network microstructure. In both the liquid-phase 4-NP reduction process and the gas-phase $\mathrm{CO}$ oxidation process, the $\mathrm{AuNPs}^{\circledR} \mathrm{ZnO}$ paper exhibited excellent practical utility and high catalytic reactivity [30,34,35]. This facile technique can be extended to various metal NPs, and thus has potential applicability for the on-paper synthesis of bimetallic hybrid nanocatalysts for further functionalization. 
In the present study, the synthesis of $\mathrm{Au}_{\text {core }}-\mathrm{Ag}_{\text {shell }}$ bimetallic NPs, denoted as $\mathrm{AuAgNPs}$, on $\mathrm{ZnO}$ whiskers was investigated. The on-paper synthesis of AuAgNPs was also conducted. The catalytic performance of the as-prepared $\mathrm{AuAgNPs}{ }^{\circledR} \mathrm{ZnO}$ whiskers and paper were evaluated in the liquid-phase reduction of 4-NP.

\section{Results and Discussion}

\subsection{AuAgNPs Synthesis on the ZnO Whiskers}

$\mathrm{ZnO}$ whiskers were added to a neutral solution of $\mathrm{HAuCl}_{4}$ and the suspension was heated at reflux at $100{ }^{\circ} \mathrm{C}$ for $48 \mathrm{~h}$ before filtration. The treated whiskers were thoroughly washed with deionized water, dried and calcined at $300{ }^{\circ} \mathrm{C}$ for $4 \mathrm{~h}$. The $\mathrm{ZnO}$ whiskers then changed color from white to pink-purple, as shown in Figure 1(a,b). Furthermore, transmission electron microscopy (TEM) analysis suggested that many NPs with a particle size less than $5 \mathrm{~nm}$ were synthesized on the surfaces of the $\mathrm{ZnO}$ whiskers (Figure 1(b)). Subsequently, the $\mathrm{HAuCl}_{4}$-treated whiskers were added to an aqueous solution of $\mathrm{AgNO}_{3}$ and the suspension was mixed with aqueous solutions of sodium citrate and hydroquinone for $1 \mathrm{~h}$ before filtration. The obtained whiskers were thoroughly washed with deionized water and dried at room temperature for $24 \mathrm{~h}$ to afford a yellow-brown product (Figure 1(c)). As shown in Figure 1(d), high-resolution TEM imaging of the resulting NPs indicates that there are electron-dense and electron-lucent layers inside and outside the NPs, respectively. The TEM images suggest that many NPs with core-shell nanostructures were synthesized on the $\mathrm{ZnO}$ whiskers.

Figure 1. Optical and TEM images for (a) the original $\mathrm{ZnO}$ whiskers, and $\mathrm{ZnO}$ whiskers treated with (b) $\mathrm{HAuCl}_{4}$ and (c) $\mathrm{HAuCl}_{4}$ and $\mathrm{AgNO}_{3}$; (d) High-resolution TEM images of $\mathrm{NPs}$ on $\mathrm{ZnO}$ whiskers treated with $\mathrm{HAuCl}_{4}$ and $\mathrm{AgNO}_{3}$.
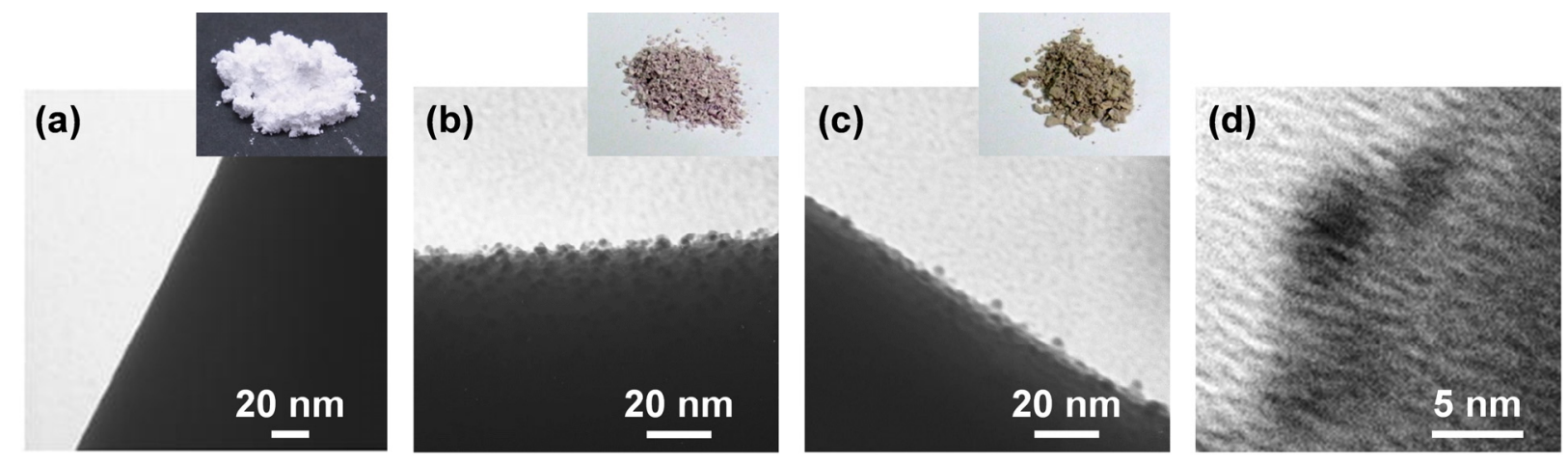

Energy dispersive X-ray spectroscopy (EDS) analysis of the NPs confirms the coexistence of Au and $\mathrm{Ag}$ (Figure 2). 
Figure 2. EDS spectrum of NPs on $\mathrm{ZnO}$ whiskers treated with $\mathrm{HAuCl}_{4}$ and $\mathrm{AgNO}_{3}$.

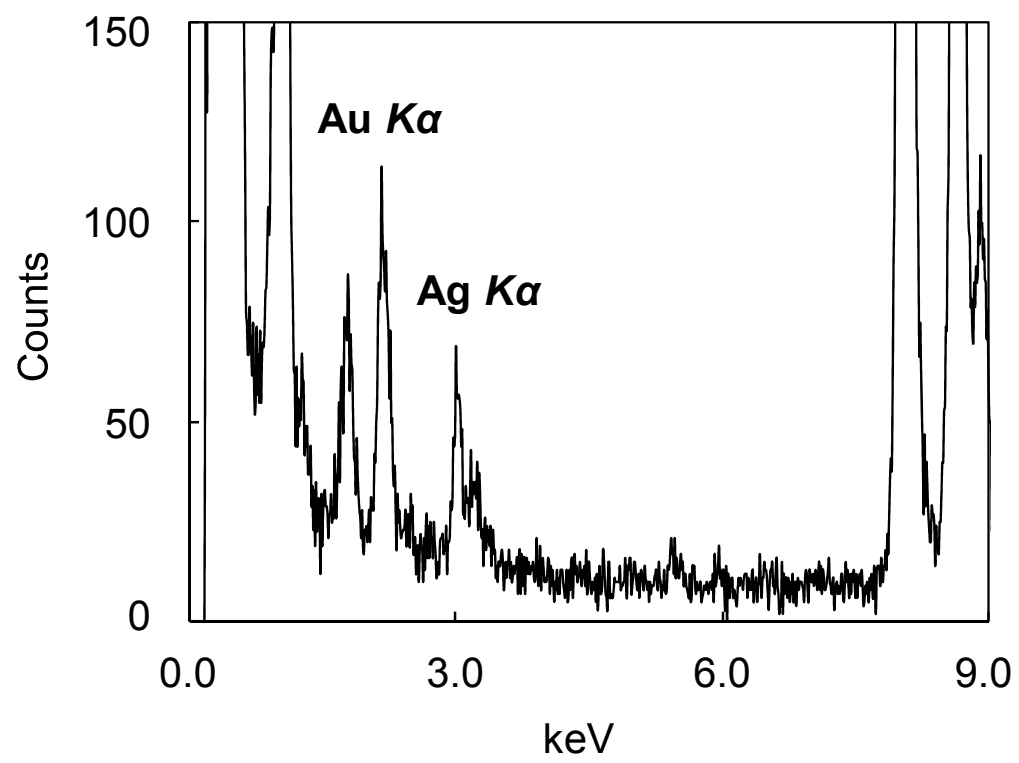

Figure 3 shows the X-ray photoelectron spectroscopy (XPS) spectra for the original ZnO whiskers, $\mathrm{ZnO}$ whiskers treated with $\mathrm{HAuCl}_{4}$ and $\mathrm{ZnO}$ whiskers treated with $\mathrm{HAuCl}_{4}$ and $\mathrm{AgNO}_{3}$.

Figure 3. XPS spectra for (a) the original $\mathrm{ZnO}$ whiskers, and $\mathrm{ZnO}$ whiskers treated with (b) $\mathrm{HAuCl}_{4}$ and (c) $\mathrm{HAuCl}_{4}$ and $\mathrm{AgNO}_{3}$.

Ag $3 d$

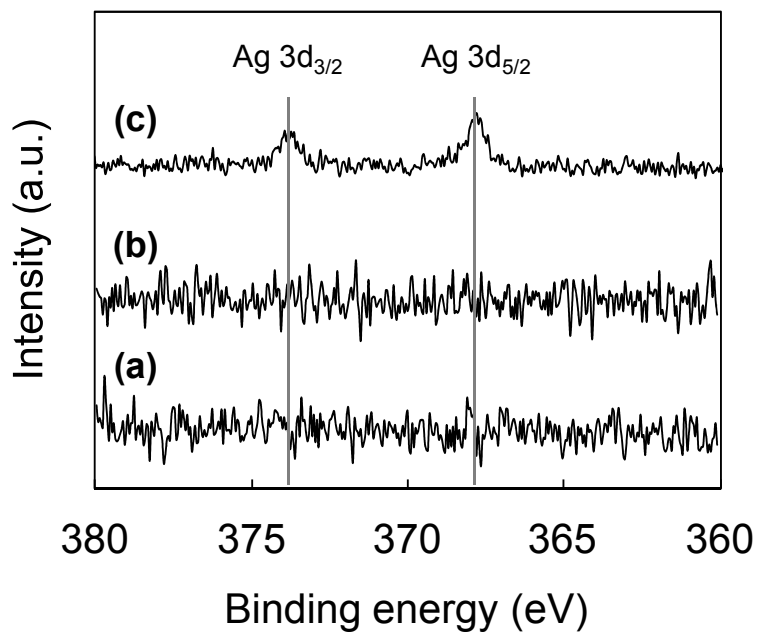

$A u 4 f \& Z n 3 p$

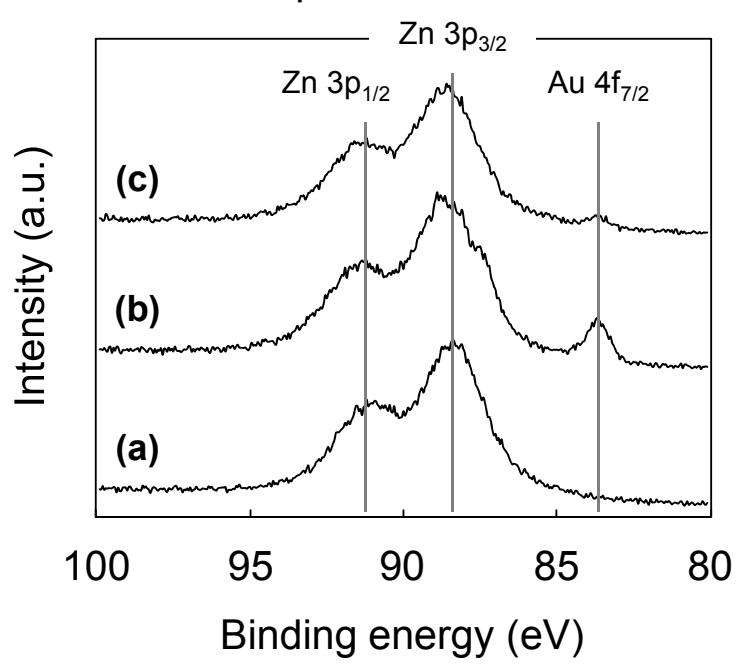

When the $\mathrm{ZnO}$ whiskers were treated with $\mathrm{HAuCl}_{4}$, the $\mathrm{Au}_{4} \mathrm{f}_{7 / 2}$ peak at $c a .83 .8 \mathrm{eV}$, assigned to the characteristic peak of $\mathrm{Au}(0)$ [36], appears (Figure 3(b)), which indicates the NPs shown in Figure 1(b) correspond to AuNPs. On the basis of previous reports for the synthesis of Au on metal oxides, via a deposition-precipitation method [37,38], it is proposed that the formation of AuNPs on the $\mathrm{ZnO}$ whiskers proceeds as follows: (1) $\mathrm{Au}(\mathrm{III})$ complex anions in an aqueous solution of $\mathrm{HAuCl}_{4}$ change from $\left[\mathrm{AuCl}_{4}\right]^{-}$to $\left[\mathrm{Au}(\mathrm{OH})_{4}\right]^{-}$at $\mathrm{pH} 7.5-8.0 ;(2)$ the $\left[\mathrm{Au}(\mathrm{OH})_{4}\right]^{-}$ions are adsorbed onto the surfaces of the positively charged $\mathrm{ZnO}$ whiskers under neutral conditions [39] due to electrostatic interactions; (3) thermal treatment at $100{ }^{\circ} \mathrm{C}$ leads to the formation of $\mathrm{Au}(\mathrm{OH})_{3}$ on the surfaces of the $\mathrm{ZnO}$ 
whiskers; and (4) the $\mathrm{Au}(\mathrm{OH})_{3}$ is thermally reduced to AuNPs under calcination treatment at $300{ }^{\circ} \mathrm{C}$. When the AuNPs ${ }^{\circledR} \mathrm{ZnO}$ whiskers are treated with $\mathrm{AgNO}_{3}$, sodium citrate and hydroquinone, the two peaks for $\mathrm{Ag} 3 \mathrm{~d}_{3 / 2}$ and $\mathrm{Ag} 3 \mathrm{~d}_{5 / 2}$ at $c a .373 .9 \mathrm{eV}$ and $c a .367 .8 \mathrm{eV}$, respectively, assigned to the characteristic peaks of $\operatorname{Ag}(0)$ [40], appear, and the intensity for the $\mathrm{Au}(0)$ peak at $c a .83 .8 \mathrm{eV}$ decreases (Figure 3(c)). This indicates the formation of an Ag layer on the surfaces of the AuNPs. Hydroquinone has a weak redox potential $\left(E^{\circ}=-0.7 \mathrm{~V} v s\right.$. NHE) [41], and is therefore unable to reduce the $\mathrm{Ag}^{+}$ions that are isolated in solution $\left(\mathrm{Ag}^{+} / \mathrm{Ag}^{0}, E^{\circ}=-1.8 \mathrm{~V}\right)$. It can, however, reduce $\mathrm{Ag}^{+}$in the presence of $\mathrm{Ag}^{0}$ clusters or NPs $\left(E^{\circ}=+0.799 \mathrm{~V} v s\right.$. NHE) $[42,43]$. Furthermore, Lim et al. have recently reported the successful formation of an $\mathrm{Ag}_{\text {shell }}$ layer on $\mathrm{Au}_{\text {core }} \mathrm{NPs}$ using hydroquinone as the reducing agent [44]. On the basis of these results and previous reports, it is proposed that $\mathrm{Au}_{\text {core }}-\mathrm{Ag}_{\text {shell }}$ bimetallic NPs, as shown in Figure 1(d), were successfully synthesized on the surfaces of $\mathrm{ZnO}$ whiskers via a multi-step process.

\subsection{In Situ Synthesis of AuAgNPs onto ZnO Paper}

As described above, very small $\mathrm{Au}_{\text {core }}-\mathrm{Ag}_{\text {shell }}$ bimetallic NPs were successfully immobilized onto the $\mathrm{ZnO}$ whiskers. However, these as-prepared AuAgNPs ${ }^{\circledR} \mathrm{ZnO}$ whiskers were somewhat difficult to handle, since the $\mathrm{ZnO}$ whiskers are fine fibers (Figure 1). The proposed on-paper synthesis technique is a promising strategy to solve this issue [30]. In this study, the on-paper synthesis of AuAgNPs was carried out; $\mathrm{ZnO}$ whiskers were initially incorporated into an easy-to-handle paper matrix, upon which the AuAgNPs were synthesized in situ. Firstly, the $\mathrm{ZnO}$ whiskers were embedded into a paper matrix consisting of ceramic, glass and pulp fibers using our established papermaking technique [45]. The dual polyelectrolyte retention system, which involves the sequential addition of cationic and anionic polyelectrolytes, allowed a quantitative retention of the added materials, which included the fine $\mathrm{ZnO}$ whiskers. The paper composite was then thermally treated at $700{ }^{\circ} \mathrm{C}$ for $30 \mathrm{~min}$ to remove the organic pulp fibers and enhance the physical strength by sintering the glass fibers. Subsequently, the AuAgNPs were synthesized in situ on the as-prepared $\mathrm{ZnO}$ paper in a multi-step preparation process, similar to that for the AuAgNPs ${ }^{\circledR} \mathrm{ZnO}$ whiskers. Figure 4 shows optical images for the original $\mathrm{ZnO}$ paper, AuNPs ${ }^{\circledR} \mathrm{ZnO}$ paper and AuAgNPs ${ }^{\circledR} \mathrm{ZnO}$ paper.

Figure 4. Optical images of (a) the original $\mathrm{ZnO}$ paper, (b) $\mathrm{AuNPs}^{\circledR} \mathrm{ZnO}$ paper and (c) AuAgNPs ${ }^{\circledR} \mathrm{ZnO}$ paper. The paper composite size is $1.8 \times 10^{2} \mathrm{~mm}^{2}$.
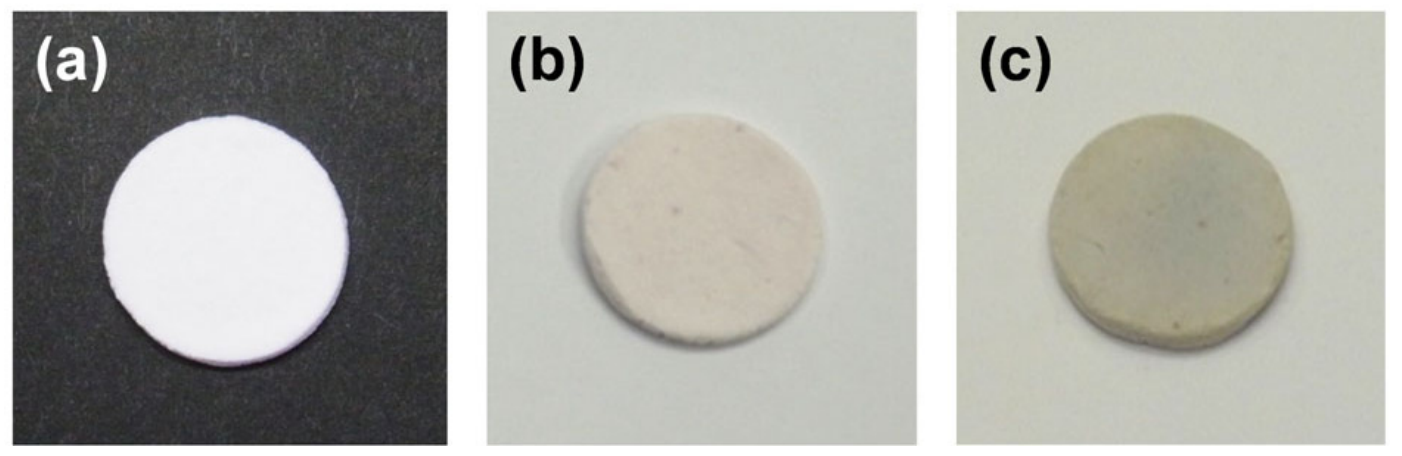

These paper composites are cardboard-like materials. Even after sonication in water for 30 min, no fiber components, including the $\mathrm{ZnO}$ whiskers, fell from the paper composites. This suggests that the $\mathrm{AuAgNPs}{ }^{\circledR} \mathrm{ZnO}$ whiskers are strongly incorporated in the paper matrix and the AuAgNPs ${ }^{\circledR} \mathrm{ZnO}$ paper 
has a high physical strength. The metal NPs ${ }^{\circledR} \mathrm{ZnO}$ paper composites have a highly porous structure; the peak pore size and the porosity are $c a .15 \mu \mathrm{m}$ and $c a .80 \%$, respectively [30]. Thus, the AuAgNPs ${ }^{\circledR} \mathrm{ZnO}$ paper was porous, flexible and easy-to-handle, allowing excellent practical utility.

\subsection{Catalytic Performances of AuAgNPs ${ }^{\circledR} \mathrm{ZnO}$ Whisker and Paper}

4-NP is known to be an anthropogenic pollutant, since it is carcinogenic, mutagenic, and cyto- and embryonic-toxic. Hence, it is desirable to develop an effective method for the removal of 4-NP. A promising approach involves the catalytic reduction of 4-NP to 4-AP, an important intermediate for the manufacture of analgesic and antipyretic drugs [46]. In this study, the catalytic performances of the AuAgNPs ${ }^{\circledR} \mathrm{ZnO}$ whiskers and paper were investigated for the aqueous reduction of 4-NP to 4-AP with $\mathrm{NaBH}_{4}$. Figure 5(a) shows the UV-vis absorption spectra recorded throughout the catalytic reduction of 4-NP over the AuAgNPs ${ }^{\circledR} \mathrm{ZnO}$ whiskers.

Figure 5. Catalytic performances of the AuAgNPs ${ }^{\circledR} \mathrm{ZnO}$ whiskers. (a) UV-vis absorption spectra throughout the catalytic reduction of 4-NP over $\mathrm{AuAgNPs}{ }^{\circledR} \mathrm{ZnO}$ whiskers, (b) $\ln \left(A_{t} / A_{0}\right)$ versus reaction time for the reduction of 4-NP; AuAgNPs ${ }^{\circledR} \mathrm{ZnO}$ whiskers (circles), AuNPs ${ }^{\circledR} \mathrm{ZnO}$ whiskers (squares), AgNPs ${ }^{\circledR} \mathrm{ZnO}$ whiskers (triangles) and the original $\mathrm{ZnO}$ whiskers (diamonds). $A_{0}$ and $A_{\mathrm{t}}$ are the initial absorbance and absorbance at time $t$ at $400 \mathrm{~nm}$. AuAgNPs ${ }^{\circledR} \mathrm{ZnO}$ whisker: $\mathrm{Au}=0.07 \mu \mathrm{mol}$ and $\mathrm{Ag}=0.03 \mu \mathrm{mol}$, AuNPs ${ }^{\circledR} \mathrm{ZnO}$ whisker: $\mathrm{Au}=0.1 \mu \mathrm{mol}, \mathrm{AgNPs}^{\circledR} \mathrm{ZnO}$ whisker: $\mathrm{Ag}=0.1 \mu \mathrm{mol}$. 4-NP: $15 \mu \mathrm{mol}, \mathrm{NaBH}_{4}: 3.0 \mathrm{mmol}$.
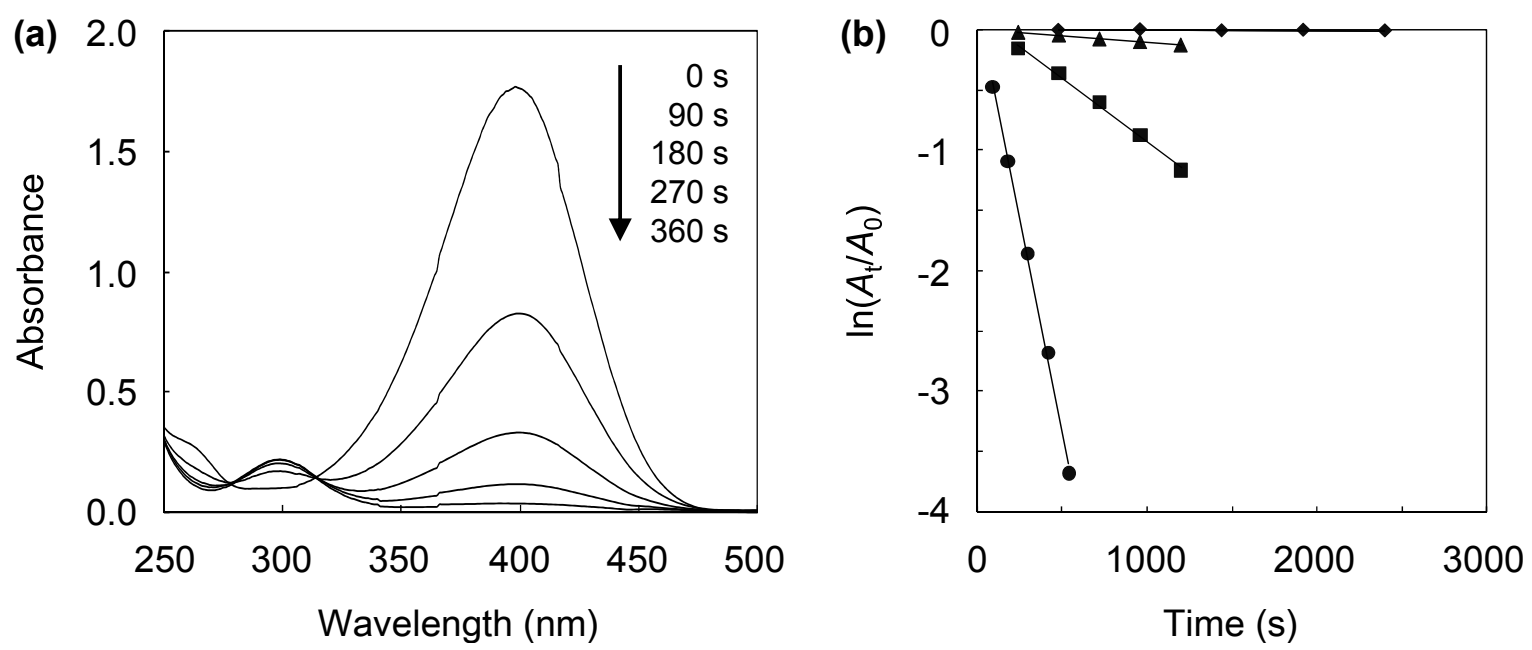

The characteristic peak for 4-NP at ca. $400 \mathrm{~nm}$, ascribed to the 4-nitrophenolate ion [3,10], gradually decreases, while a new peak at $c a .300 \mathrm{~nm}$, assigned to 4-AP [3,10] appears. The reaction with the $\mathrm{AuAgNPs}{ }^{\circledR} \mathrm{ZnO}$ whiskers was almost complete within $360 \mathrm{~s}$ under continuous stirring. Figure 5(b) shows the $\ln \left(A_{\mathrm{t}} / A_{0}\right)\left(A_{\mathrm{t}}\right.$ : absorbance at $400 \mathrm{~nm}$ at the reaction time $t, A_{0}$ : absorbance at $400 \mathrm{~nm}$ at the initial stage) as a function of reaction time for the $\mathrm{AuAgNP}^{@} \mathrm{ZnO}$ whiskers, AuNPs ${ }^{\circledR} \mathrm{ZnO}$ whiskers, AgNPs ${ }^{\circledR} \mathrm{ZnO}$ whiskers and original $\mathrm{ZnO}$ whiskers. In each case, a linear correlation was observed, which suggests that the 4-NP reduction, with an excess amount of $\mathrm{NaBH}_{4}$, follows pseudo-first-order kinetics [10]. The pseudo-first-order reaction rate constants $(k)$ for the 
AuAgNPs ${ }^{\circledR} \mathrm{ZnO}$ whiskers, AuNPs ${ }^{\circledR} \mathrm{ZnO}$ whiskers, $\mathrm{AgNPs}^{\circledR} \mathrm{ZnO}$ whiskers and $\mathrm{ZnO}$ whiskers were estimated from each slope to be $7.0 \times 10^{-3} \mathrm{~s}^{-1}, 1.1 \times 10^{-3} \mathrm{~s}^{-1}, 1.0 \times 10^{-4} \mathrm{~s}^{-1}$ and $3.0 \times 10^{-6} \mathrm{~s}^{-1}$, respectively. The original $\mathrm{ZnO}$ whiskers exhibit an extremely low catalytic efficiency, indicating that the metal NPs synthesized onto the $\mathrm{ZnO}$ whiskers play a key role in this reaction. The AuNPs ${ }^{\circledR} \mathrm{ZnO}$ whiskers demonstrate a higher catalytic efficiency than the $\operatorname{AgNPs}^{\circledR} \mathrm{ZnO}$ whiskers, suggesting the AuNPs have a superior catalytic activity to the AgNPs. It is noteworthy that the AuAgNPs ${ }^{\circledR} \mathrm{ZnO}$ whiskers had the highest catalytic efficiency among the test samples; the $k$ value for the AuAgNPs ${ }^{\circledR} \mathrm{ZnO}$ whiskers $\left(7.0 \times 10^{-3} \mathrm{~s}^{-1}\right)$ was $1.2-3.3$ times larger than those for the many metal nanocatalysts previously reported, such as AuNP ${ }^{\circledR}$ cellulose single nanofibers $\left(5.9 \times 10^{-3} \mathrm{~s}^{-1}\right)$ [3], dendric Ag/Au bimetallic nanostructures $\left(6.07 \times 10^{-3} \mathrm{~s}^{-1}\right)$ [19], AuNPs/poly(amidoamine) dendrimer $\left(3.7 \times 10^{-3} \mathrm{~s}^{-1}\right)$ [47] and spongy Au nanocrystals $\left(2.1 \times 10^{-3} \mathrm{~s}^{-1}\right)$ [48]. Figure 6 shows influence of the $\mathrm{Au} / \mathrm{Ag}$ ratio on the turnover frequency (TOF) for the $\mathrm{AuAgNPs}{ }^{\circledR} \mathrm{ZnO}$ whiskers in the reduction of 4-NP.

Figure 6. Turnover frequencies (TOFs) for the AuAgNPs ${ }^{\circledR} \mathrm{ZnO}$ whiskers in the reduction of 4-NP, as a function of $\mathrm{Au}$ and $\mathrm{Ag}$ mol\%. The total amount of $\mathrm{Au}$ and $\mathrm{Ag}$ : $0.1 \mu \mathrm{mol}$, 4-NP: $15 \mu \mathrm{mol}, \mathrm{NaBH}_{4}: 3.0 \mathrm{mmol}$.

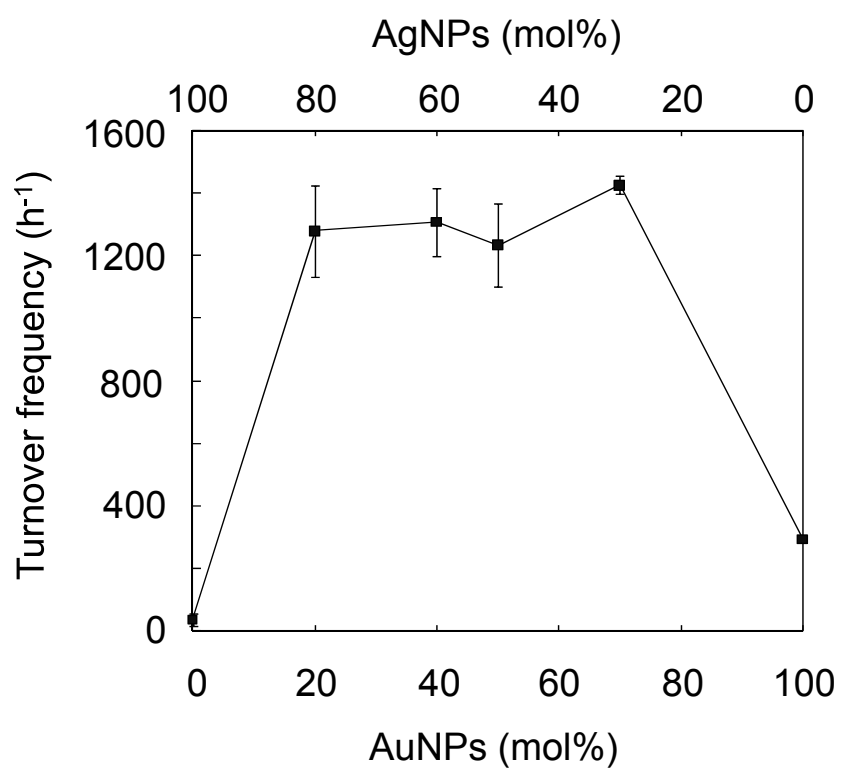

Although the total amount of $\mathrm{Au}$ and $\mathrm{Ag}$ was constant $(0.1 \mu \mathrm{mol})$ in all test samples, the $\mathrm{Au}_{\text {core }}-\mathrm{Ag}_{\text {shell }}$ bimetallic NPs exhibited a much higher TOF than the monometallic equivalents at all $\mathrm{Au} / \mathrm{Ag}$ ratios $(7 / 3,5 / 5,4 / 6,2 / 8)$ studied. The maximum TOF ( $\left.c a .1400 \mathrm{~h}^{-1}\right)$ was achieved with an $\mathrm{Au} / \mathrm{Ag}$ ratio of 7/3, and was 5-40 fold higher those for the monometallic NPs. Esumi et al. have proposed that the AuNPs-catalyzed 4-NP reduction, with an excess of $\mathrm{NaBH}_{4}$, proceeds in two steps: (1) the diffusion and adsorption of 4-NP to catalyst surface; and (2) an electron transfer mediated by the catalyst surface from $\mathrm{BH}_{4}{ }^{-}$to $4-\mathrm{NP}[47,49]$. They concluded that the first step is the rate limiting step in the 4-NP reduction. Thus, the interesting phenomenon observed in this study may be attributed to the electronic ligand effect between the core and shell atoms [21,22,24]. Since the ionization potentials for $\mathrm{Ag}$ and $\mathrm{Au}$ are $7.58 \mathrm{eV}$ and $9.22 \mathrm{eV}$, respectively, an electronic transfer could occur from $\mathrm{Ag}_{\text {shell }}$ to $\mathrm{Au}_{\text {core }}$ [25], resulting in a decrease in electron density on the shell surfaces of the 
$\mathrm{Au}_{\text {core }}-\mathrm{Ag}_{\text {shell }}$ bimetallic hybrid NPs. Such electron-deficient surfaces would favor the adsorption of 4-nitrophenolate anions, and lead to excellent 4-NP reduction efficiencies.

Figure 7 shows the 4-NP reduction performance for the $\mathrm{AuAgNPs}^{\circledR} \mathrm{ZnO}$ paper.

Figure 7. Reusability of $\mathrm{AuAgNPs}^{\circledR} \mathrm{ZnO}$ paper in the 4-NP reduction. Total amount of $\mathrm{Au}$ and $\mathrm{Ag}$ : $0.01 \mu \mathrm{mol}(\mathrm{Au}=0.007 \mu \mathrm{mol}$ and $\mathrm{Ag}=0.003 \mu \mathrm{mol}), 4-\mathrm{NP}: 15 \mu \mathrm{mol}$, $\mathrm{NaBH}_{4}: 3.0 \mathrm{mmol}$.

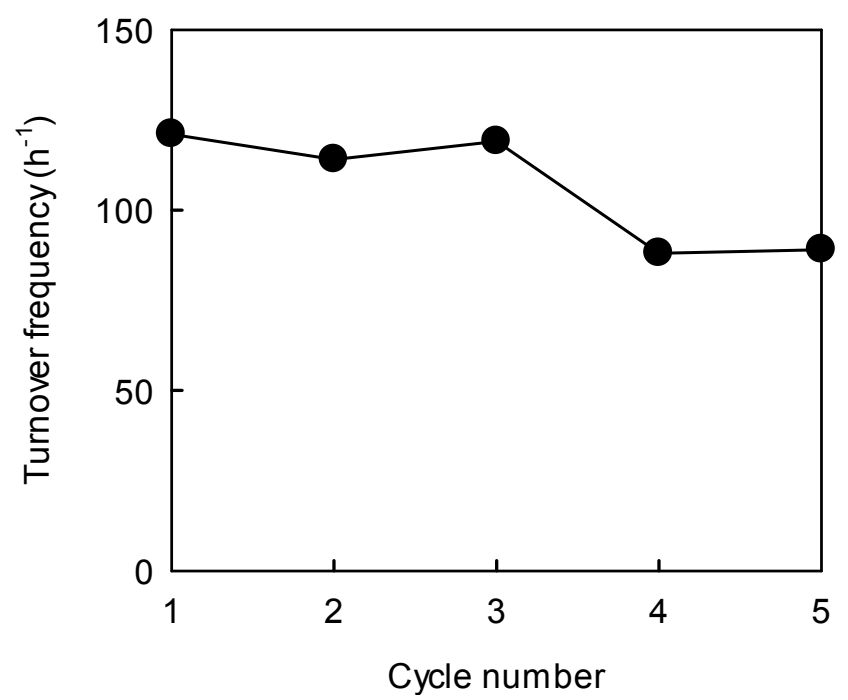

The reusability of the $\mathrm{AuAgNPs}{ }^{\circledR} \mathrm{ZnO}$ paper was evaluated from the changes in TOF over a five-cycle test: the sequential procedure for the 4-NP reduction reaction involved washing with water and drying at room temperature between each cycle of the test. The TOF value for the AuAgNPs ${ }^{\circledR} \mathrm{ZnO}$ paper was $c a .120 \mathrm{~h}^{-1}$ in the first cycle, which is lower than that for the AuAgNPs ${ }^{\circledR} \mathrm{ZnO}$ whiskers. This may be because the accessibility for the reactants to the AuAgNPs ${ }^{\circledR} \mathrm{ZnO}$ paper was insufficient under continuous stirring due to its large size ( $c a .15 \mathrm{~mm}$ in diameter) in comparison to the fine AuAgNPs ${ }^{\circledR} \mathrm{ZnO}$ whiskers (fiber length: 2-50 $\mu \mathrm{m}$, fiber diameter: 0.2-3.0 $\mu \mathrm{m}$ ), although the unique porous microstructure of the metal NPs ${ }^{\circledR} \mathrm{ZnO}$ paper, with an open porous network throughout, was favorable for the efficient transport of the 4-NP to the NPs surfaces under static conditions [30,35]. While the AuAgNPs ${ }^{\circledR} \mathrm{ZnO}$ whiskers exhibited a higher catalytic performance, they remain difficult to handle and hard to separate from the reaction system owing to their fine size (Figure 1(c)). Conversely, the AuAgNPs ${ }^{\circledR} \mathrm{ZnO}$ paper is easy-to-handle in practical terms due to its simple paper form (Figure 4(c)), allowing a high reusability. In fact, the $\mathrm{AuAgNPs}^{\circledR} \mathrm{ZnO}$ paper was easily recovered from the reaction solution after each performance test, and demonstrated a TOF of $c a .90 \mathrm{~h}^{-1}$ after the fifth cycle. The atomic absorption analysis confirmed that no AuAgNPs dropped out of the paper composite during the catalytic reaction. Thus this decrease in the catalytic efficiency may be due to the inevitable aggregation of metal NPs during the 4-NP reduction $[10,35]$ and/or the degradation of an $\mathrm{Au}_{\text {core }}-\mathrm{Ag}_{\text {shell }}$ nanostructure. It is difficult to fully suppress the deterioration of the metal NPs after repeated use, but the immobilization of the AuAgNPs on a paper matrix via our on-paper synthesis technique has provided a high degree of practical utility for the very small AuAgNPs. Furthermore, the highly porous structure of the paper composites provide a great potential for application to flow-type processes, which can be applied to continuous processes, regardless of liquid- [50] and gas-phase reactions [28-30,33,34,45]. 
Thus the AuAgNPs ${ }^{\circledR} \mathrm{ZnO}$ paper with paper-like characteristics is a promising practical material for a variety of catalytic processes.

\section{Experimental Section}

\subsection{Materials}

Ceramic fibers $\left(\mathrm{SiO}_{2}: 52 \mathrm{wt} \%, \mathrm{Al}_{2} \mathrm{O}_{3}: 48 \mathrm{wt} \%\right)$ and $\mathrm{ZnO}$ whiskers (fiber length: $2-50 \mu \mathrm{m}$, fiber diameter: 0.2-3.0 $\mu \mathrm{m}$ ) were obtained from IBIDEN, Ltd. (Tokyo, Japan) and Matsushita Amtec, Ltd. (Osaka, Japan) respectively. Pulp fibers, as a matrix component in the paper fabrication process were prepared by refining a commercial bleached hardwood kraft pulp to a Canadian Standard Freeness of $300 \mathrm{~mL}$ with a Technical Association of the Pulp and Paper Industry standard beater. Glass fibers (CMLF208, Nippon Sheet Glass, Ltd., Tokyo, Japan) were used as a binding component to enhance the physical strength of the paper composite following calcination. Two types of flocculants, namely cationic poly(diallyldimethylammonium chloride) (PDADMAC; molecular weight ca. $3 \times 10^{5} \mathrm{~g} \mathrm{~mol}^{-1}$; charge density $5.5 \mathrm{meq}^{-1}$ ) and anionic polyacrylamide (A-PAM, HH-351; molecular weight ca. $4 \times 10^{6} \mathrm{~g} \mathrm{~mol}^{-1}$; charge density $0.64 \mathrm{meq} \mathrm{g}^{-1}$ ), were purchased from Aldrich, Ltd. (Sheffield, UK) and Kurita, Ltd. (Tokyo, Japan), respectively. $\mathrm{AgNO}_{3}(99.8+\%$ purity) and trisodium citrate dihydrate were obtained from Wako Pure Chemical Industries, $\mathrm{Ltd}$. $\mathrm{HAuCl}_{4} \cdot 3 \mathrm{H}_{2} \mathrm{O}(99.9 \%$ purity), hydroquinone ( $>99 \%$ purity), 4-NP (99\% purity) and sodium borohydride $\left(\mathrm{NaBH}_{4},>95 \%\right.$ purity) were purchased from Aldrich, Ltd. (Sheffield, UK). All other chemicals were of reagent grade and used without further purification.

\subsection{Preparation of $\mathrm{AuAgNPs}{ }^{\circledR} \mathrm{ZnO}$ Whiskers}

$\mathrm{Au}_{\text {core }}-\mathrm{Ag}_{\text {shell }}$ bimetallic NPs were synthesized on $\mathrm{ZnO}$ whiskers via a multi-step process. Firstly, the synthesis of the AuNPs onto the $\mathrm{ZnO}$ whiskers was conducted using a deposition-precipitation method in line, to some degree to previous reports [37,38]. An aqueous solution of $\mathrm{HAuCl}_{4}(0.2-0.5 \mathrm{mM}, 25 \mathrm{~mL})$ was adjusted to $\mathrm{pH} 7.5-8.0$ with aqueous $\mathrm{NaOH}(100 \mathrm{mM})$. The $\mathrm{ZnO}$ whiskers $(1.0 \mathrm{~g})$ were then suspended in the solution, and the mixture was refluxed at $100{ }^{\circ} \mathrm{C}$ for $48 \mathrm{~h}$ with continuous stirring. The suspension was then filtered, washed with deionized water, dried at $80{ }^{\circ} \mathrm{C}$ for $1 \mathrm{~h}$ and calcined at $300{ }^{\circ} \mathrm{C}$ for $4 \mathrm{~h}$. An Ag nanolayer was formed on the as-synthesized AuNPs as follows. The as-prepared AuNPs ${ }^{\circledR} \mathrm{ZnO}$ whiskers (400 mg) were suspended in an aqueous solution of $\mathrm{AgNO}_{3}(0.06-0.55 \mathrm{mM}$, $5 \mathrm{~mL}$ ) for $30 \mathrm{~min}$. Aqueous solutions of sodium citrate $(1.0 \%(\mathrm{w} / \mathrm{v}), 50 \mu \mathrm{L})$, as a stabilizer, and hydroquinone $(30 \mathrm{mM}, 200 \mu \mathrm{L})$, as a reducing agent, were then added to the mixture, followed by stirring for $1 \mathrm{~h}$ and filtration. Finally, the products were thoroughly washed with deionized water and dried at room temperature for $24 \mathrm{~h}$. The $\mathrm{AgNPs}^{\circledR} \mathrm{ZnO}$ whiskers were also prepared according to our previous report [31].

\subsection{Preparation of ZnO Paper by a Papermaking Technique}

The preparation of paper composites using organic and inorganic fibers, via a dual polyelectrolyte retention system, was conducted according to our previous reports [30,45]. In summary, an aqueous suspension of ceramic fibers, glass fibers and $\mathrm{ZnO}$ whiskers was mixed with PDADMAC $(0.5 \mathrm{wt} \%$ of 
total solids) and A-PAM ( $0.5 \mathrm{wt} \%$ of total solids), in that order. This mixture was then added to a water suspension of pulp fibers, and solidified through dewatering using a 200-mesh wire. The wet-state handsheets were pressed at $350 \mathrm{kPa}$ for $3 \mathrm{~min}$ and dried at $105{ }^{\circ} \mathrm{C}$ for $1 \mathrm{~h}$. The resulting paper composite, with an area of $2 \times 10^{4} \mathrm{~mm}^{2}$ and a thickness of $1.4 \mathrm{~mm}$, was composed of ceramic fibers $(4.0 \mathrm{~g})$, glass fibers $(4.0 \mathrm{~g}), \mathrm{ZnO}$ whiskers $(1.0 \mathrm{~g})$ and pulp fibers $(1.0 \mathrm{~g})$. The obtained paper composites were thermally treated at $700{ }^{\circ} \mathrm{C}$ for $30 \mathrm{~min}$ to remove any pulp fibers and to improve the physical strength through the sintering of glass fibers.

\subsection{Preparation of AuAgNPs ${ }^{\circledR} \mathrm{ZnO}$ Paper}

The in situ synthesis of AuAgNPs onto the $\mathrm{ZnO}$ paper was performed in a similar manner to that for the AuAgNPs ${ }^{\circledR} \mathrm{ZnO}$ whiskers. An aqueous solution of $\mathrm{HAuCl}_{4}(0.03 \mathrm{mM}, 80 \mathrm{~mL})$ was adjusted to $\mathrm{pH}$ 7.5-8.0 using an aqueous solution of $\mathrm{NaOH}(100 \mathrm{mM})$. The $\mathrm{ZnO}$ paper was cut into circular pieces, each with an area of $1.8 \times 10^{2} \mathrm{~mm}^{2}$ and a thickness of $1.4 \mathrm{~mm}$. The four pieces were immersed in the solution and stirred at reflux for $48 \mathrm{~h}$. The treated paper discs were removed from the solution using tweezers, thoroughly washed with deionized water, dried at $80^{\circ} \mathrm{C}$ for $1 \mathrm{~h}$ and calcined at $300{ }^{\circ} \mathrm{C}$ for $4 \mathrm{~h}$. A piece of the as-prepared AuNPs ${ }^{\circledR} \mathrm{ZnO}$ paper was then immersed in an aqueous solution of $\mathrm{AgNO}_{3}(0.001 \mathrm{mM}, 5 \mathrm{~mL})$ for $30 \mathrm{~min}$. Aqueous solutions of sodium citrate $(1.0 \%(\mathrm{w} / \mathrm{v}), 50 \mu \mathrm{L})$ and hydroquinone $(30 \mathrm{mM}, 200 \mu \mathrm{L})$ were added to the mixture and stirred for $1 \mathrm{~h}$. The obtained paper disc was thoroughly washed with deionized water and dried at room temperature for $24 \mathrm{~h}$.

\subsection{Catalytic Performance Test}

Catalytic performances towards the reduction of 4-NP were investigated in batch mode. An aqueous solution of 4-NP $(0.1 \mathrm{mM}, 150 \mathrm{~mL})$ was initially mixed with $\mathrm{NaBH}_{4}(3.0 \mathrm{mmol})$, as the reducing agent. The AuNPs ${ }^{\circledR} \mathrm{ZnO}$ whiskers, AgNPs ${ }^{\circledR} \mathrm{ZnO}$ whiskers or $\mathrm{AuAgNPs}{ }^{\circledR} \mathrm{ZnO}$ whiskers were then added to the solution. In all cases, the total amount of $\mathrm{Au}$ and $\mathrm{Ag}$ remained constant at $0.1 \mu \mathrm{mol}$. Reactions were carried out at $25{ }^{\circ} \mathrm{C}$ with continuous stirring. At given times, samples $(1.0 \mathrm{~mL})$ were taken, filtered through a $0.2 \mu \mathrm{m}$ membrane filter (Chromatodisk, GL Sciences, Ltd.) and analyzed via UV-vis. UV-vis spectra of the reaction solutions $(1.0 \mathrm{~mL})$ were recorded at room temperature using a U-3000 spectrophotometer (Hitachi, Japan). According to a previous report [10], the rate constants for the reduction process were determined by measuring the change in absorbance at $400 \mathrm{~nm}$ as a function of time. The reusability of the AuAgNPs ${ }^{\circledR} \mathrm{ZnO}$ paper was also evaluated from the changes in TOF value during a five-cycle test: the sequential procedures of the 4-NP reduction reaction, washing with water and drying at room temperature were conducted in each cycle of the test.

\subsection{Analyses}

The levels of $\mathrm{Au}$ and $\mathrm{Ag}$ were determined using atomic absorption spectrophotometry on a Shimadzu AA-6600F instrument. TEM and EDS analyses were performed using a JEM-2010FEF instrument (JEOL, Ltd., Tokyo, Japan) at a $200 \mathrm{kV}$ accelerating voltage. The chemical states of the component elements were analyzed by XPS (AXIS-HSi spectrometer, Shimadzu/Kratos, Ltd., Kyoto, Japan) using a monochromatic $\mathrm{Al} K \alpha \mathrm{X}$-ray source $(1486.6 \mathrm{eV})$ with a $12 \mathrm{kV}$ voltage and $10 \mathrm{~mA}$ current. The 
binding energies for all spectra were determined with respect to the $\mathrm{C} 1 \mathrm{~s}$ reference signal (unoxidized C-C bond) at $285.0 \mathrm{eV}$.

\section{Conclusions}

We have demonstrated the successful synthesis of $\mathrm{Au}-\mathrm{Ag}$ bimetallic hybrid NPs with $\mathrm{Au}_{\text {core }}-\mathrm{Ag}_{\text {shell }}$ nanostructures on $\mathrm{ZnO}$ whiskers. The $\mathrm{AuAgNPs}{ }^{\circledR} \mathrm{ZnO}$ whiskers exhibit an excellent catalytic efficiency in the aqueous reduction of 4-NP to 4-AP: the TOF for the AuAgNPs ${ }^{\circledR} \mathrm{ZnO}$ whiskers was 5-40 fold higher than those for the monometallic equivalents. This may be caused by the electronic ligand effect. Electron-deficient shell surfaces, derived from $\mathrm{Au}_{\mathrm{core}}-\mathrm{Ag}_{\text {shell }}$ nanostructures, would be advantageous in the adsorption of 4-nitrophenolate anions, which would lead to an excellent 4-NP reduction efficiency. The on-paper synthesis of the AuAgNPs was also accomplished, and the resulting AuAgNPs ${ }^{\circledR}$ ZnO paper had paper-like characteristics and possessed an excellent practical utility. Thus, the on-paper synthesis of bimetallic NPs is a promising technique to potentially promote the practical use of highly-functional bimetallic nanocatalysts across a wide range of chemical industries.

\section{Acknowledgments}

This research was supported by a Research Fellowship for Young Scientists from the Japan Society for the Promotion of Science (H.K.).

\section{References}

1. Cortright, R.D.; Davda, R.R.; Dumesic, J.A. Hydrogen from catalytic reforming of biomass-derived hydrocarbons in liquid water. Nature 2002, 418, 964-967.

2. Nishihata, Y.; Mizuki, J.; Akao, T.; Tanaka, H.; Uenishi, M.; Kimura, M.; Okamoto, T.; Hamada, N. Self-regeneration of a Pd-perovskite catalyst for automotive emissions control. Nature 2002, 418, 164-167.

3. Koga, H.; Tokunaga, E.; Hidaka, M.; Umemura, Y.; Saito, T.; Isogai, A.; Kitaoka, T. Topochemical synthesis and catalysis of metal nanoparticles exposed on crystalline cellulose nanofibers. Chem. Commun. 2010, 46, 8567-8569.

4. Zhou, B.; Han, S.; Raja, R.; Somorjai, G.A. Nanotechnology in Catalysis; Springer Science and Business Media: New York, NY, USA, 2007; Volume 3.

5. Campelo, J.M.; Luna, D.; Luque, R.; Marinas, J.M.; Romero, A.A. Sustainable preparation of supported metal nanoparticles and their applications in catalysis. ChemSusChem 2009, 2, $18-45$.

6. Haruta, M. When gold is not noble: Catalysis by nanoparticles. Chem. Rec. 2003, 3, 75-87.

7. Bond, G.C.; Louis, C.; Thompson, D.T.; Hutchings, G.J. Catalysis by Gold; Imperial College: London, UK, 2006.

8. Hashmi, A.S.K.; Hutching, G.J. Gold catalysis. Angew. Chem. Int. Ed. 2006, 45, 7896-7936.

9. Ishida, T.; Haruta, M. Gold catalysts: Towards sustainable chemistry. Angew. Chem. Int. Ed. 2007, 46, 7154-7156.

10. Kuroda, K.; Ishida, T.; Haruta, M. Reduction of 4-nitrophenol to 4-aminophenol over Au nanoparticles deposited on PMMA. J. Mol. Catal. A Chem. 2009, 298, 7-11. 
11. Wong, K.; Zeng, Q.; Yu, A. Gold catalysts: A new insight into the molecular adsorption and CO oxidation. Chem. Eng. J. 2009, 155, 824-828.

12. Zhu, Y.; Jin, R.; Sun, Y. Atomically monodisperse gold nanoclusters catalysts with precise core-shell structure. Catalysts 2011, 1, 3-17.

13. Armer, B.; Schmidbaur, H. Organogoldchemie. Angew. Chem. 1970, 82, 120-133.

14. Bond, G.C. The catalytic properties of gold. Gold Bull. 1972, 5, 11-13.

15. Luo, J.; Wang, L.; Mott, D.; Njoki, P.N.; Lin, Y.; He, T.; Xu, Z.; Wanjana, B.N.; Lim, I.; Zhong, C.J. Core/shell nanoparticles as electrocatalysts for fuel cell reactions. Adv. Mater. 2008, 20, 4342-4347.

16. Chiang, W.H.; Sankaran, R.M. Synergistic effects in bimetallic nanoparticles for low temperature carbon nanotube growth. Adv. Mater. 2008, 20, 4857-4861.

17. Xu, C.X.; Wang, L.Q.; Wang, R.Y.; Wang, K.; Zhang, Y.; Tian, F.; Ding, Y. Nanotubular mesoporous bimetallic nanostructures with enhanced electrocatalytic performance. Adv. Mater. 2009, 21, 2165-2169.

18. Zhang, Q.B.; Xie, J.P.; Liang, J.; Lee, J.Y. Synthesis of monodisperse Ag-Au alloy nanoparticles with independently tunable morphology, composition, size, and surface chemistry and their 3-D superlattices. Adv. Funct. Mater. 2009, 19, 1387-1398.

19. Huang, J.; Vongehr, S.; Tang, S.; Lu, H.; Shen, J.; Meng, X. Ag dendrite-based Au/Ag bimetallic nanostructures with strongly enhanced catalytic activity. Langmuir 2009, 25, 11890-11896.

20. Peng, X.; Pan, Q.; Rempel, G.L.; Wu, S. Synthesis, characterization, and application of PdPt and PdRh bimetallic nanoparticles encapsulated within amine-terminated poly(amidoamine) dendrimers. Catal. Commun. 2009, 11, 62-66.

21. Toshima, N.; Harada, M.; Yonezawa, T.; Kushihashi, K.; Asakura, K. Structural-analysis of polymer-protected $\mathrm{Pd} / \mathrm{Pt}$ bimetallic clusters as dispersed catalysts by using extended X-ray absorption fine-structure spectroscopy. J. Phys. Chem. 1991, 95, 7448-7453.

22. Toshima, N.; Yonezawa, T. Bimetallic nanoparticles-Novel materials for chemical and physical applications. New J. Chem. 1998, 22, 1179-1201.

23. Matsushita, T.; Shiraishi, Y.; Horiuchi, S.; Toshima, N. Synthesis and catalysis of polymer-protected $\mathrm{Pd} / \mathrm{Ag} / \mathrm{Rh}$ trimetallic nanoparticles with a core-shell structure. Bull. Chem. Soc. Jpn. 2007, 80, 1217-1225.

24. Toshima, N.; Ito, R.; Matsushita, T.; Shiraishi, Y. Trimetallic nanoparticles having a Au-core structure. Catal. Today 2007, 122, 239-244.

25. Tokonami, S.; Morita, N.; Takasaki, K.; Toshima, N. Novel synthesis, structure, and oxidation catalysis of Ag/Au bimetallic nanoparticles. J. Phys. Chem. C 2010, 114, 10336-10341.

26. Kim, M.J.; Lee, K.Y.; Jeong, G.H.; Jang, J.; Han, S.W. Fabrication of Au-Ag alloy nanoprisms with enhanced catalytic activity. Chem. Lett. 2007, 36, 1350-1351.

27. Dai, J.; Yao, P.; Hua, N.; Yang, P.; Du, Y. Preparation and characterization of polymer-protected $\mathrm{Pt}^{\circledR} \mathrm{Pt} / \mathrm{Au}$ core-shell nanoparticles. J. Dispersion Sci. Technol. 2007, 28, 872-875.

28. Koga, H.; Kitaoka, T.; Wariishi, H. In situ synthesis of $\mathrm{Cu}$ nanocatalysts on $\mathrm{ZnO}$ whiskers embedded in a microstructured paper composite for autothermal hydrogen production. Chem. Commun. 2008, 5616-5618. 
29. Koga, H.; Umemura, Y.; Kitaoka, T. Design of catalyst layers by using paper-like fiber/metal nanocatalyst composites for efficient $\mathrm{NO}_{\mathrm{X}}$ reduction. Compos. Part B 2011, 42, 1108-1113.

30. Koga, H.; Kitaoka, T. On-paper synthesis of metal nanoparticles for catalytic applications. Sen' $i$ Gakkaishi 2011, 67, 141-152.

31. Koga, H.; Kitaoka, T.; Wariishi, H. In situ synthesis of silver nanoparticles on zinc oxide whiskers incorporated in a paper matrix for antibacterial applications. J. Mater. Chem. 2009, 19, 2135-2140.

32. Koga, H.; Kitaoka, T. Silver Nanoparticles; IN-TECH Education and Publishing KG: Vienna, Austria, 2010.

33. Koga, H.; Umemura, Y.; Tomoda, A.; Suzuki, R.; Kitaoka, T. In situ synthesis of platinum nanocatalysts on a microstructured paperlike matrix for the catalytic purification of exhaust gases. ChemSusChem 2010, 3, 604-608.

34. Koga, H.; Kitaoka, T.; Wariishi, H. On-paper synthesis of Au nanocatalysts from Au(III) complex ions for low-temperature CO oxidation. J. Mater. Chem. 2009, 19, 5244-5249.

35. Koga, H.; Kitaoka, T. One-step synthesis of gold nanocatalysts on a microstructured paper matrix for the reduction of 4-nitrophenol. Chem. Eng. J. 2011, 168, 420-425.

36. Qian, K.; Lv, S.; Xiao, X.; Sun, H.; Lu, J.; Luo, M.; Huang, W. Influences of $\mathrm{CeO}_{2}$ microstructures on the structure and activity of $\mathrm{Au} / \mathrm{CeO}_{2} / \mathrm{SiO}_{2}$ catalysts in $\mathrm{CO}$ oxidation. J. Mol. Catal. A 2009, 306, 40-47.

37. Haruta, M.; Tsubota, S.; Kobayashi, T.; Kageyama, H.; Genet, M.J.; Delmon, B. Low-temperature oxidation of $\mathrm{CO}$ over gold supported on $\mathrm{TiO}_{2}, \alpha-\mathrm{Fe}_{2} \mathrm{O}_{3}$, and $\mathrm{Co}_{3} \mathrm{O}_{4}$. J. Catal. 1993, 144, 175-192.

38. Bond, G.C.; Thompson, D.T. Catalysis by gold. Catal. Rev. Sci. Eng. 1999, 41, 319-388.

39. Muster, T.H.; Cole, I.S. The protective nature of passivation films on zinc: Surface charge. Corros. Sci. 2004, 46, 2319-2335.

40. Shah, M.S.A.S.; Nag, M.; Kalagara, T.; Singh, S.; Manorama, S.V. Silver on PEG-PU-TiO 2 polymer nanocomposite films: An excellent system for antibacterial applications. Chem. Mater. 2008, 20, 2455-2460.

41. Gentry, S.T.; Fredericks, S.J.; Krchnavek, R. Controlled particle growth of silver sols through the use of hydroquinone as a selective reducing agent. Langmuir 2009, 25, 2613-2621.

42. Mostafavi, M.; Marignier, J.L.; Amblard, J.; Belloni, J. Nucleation dynamics of silver aggregates simulation of photographic development processes. Radiat. Phys. Chem. 1989, 34, 605-617.

43. Linnert, T.; Mulvaney, P.; Henglein, A.; Weller, H. Long-lived nonmetallic silver clusters in aqueous solution: Preparation and photolysis. J. Am. Chem. Soc. 1990, 112, 4657-4664.

44. Lim, D.-K.; Kim, I.-J.; Nam, J.-M. DNA-embedded Au/Ag core-shell nanoparticles. Chem. Commun. 2008, 5312-5314.

45. Koga, H.; Fukahori, S.; Kitaoka, T.; Tomoda, A.; Suzuki, R.; Wariishi, H. Autothermal reforming of methanol using paper-like $\mathrm{Cu} / \mathrm{ZnO}$ catalyst composites prepared by a papermaking technique. Appl. Catal. A 2006, 309, 263-269.

46. Du, Y.; Chen, H.; Chen, R.; Xu, N. Synthesis of p-aminophenol from p-nitrophenol over nano-sized nickel catalysts. Appl. Catal. A 2004, 277, 259-264.

47. Hayakawa, K.; Yoshimura, T.; Esumi, K. Preparation of gold-dendrimer nanocomposites by laser irradiation and their catalytic reduction of 4-nitrophenol. Langmuir 2003, 19, 5517-5521. 
48. Rashid, M.H.; Bhattacharjee, R.R.; Kotal, A.; Mandal, T.K. Synthesis of spongy gold nanocrystals with pronounced catalytic activities. Langmuir 2006, 22, 7141-7143.

49. Esumi, K.; Miyamoto, K.; Yoshimura, T. Comparison of PAMAM-Au and PPI-Au nanocomposites and their catalytic activity for reduction of 4-nitrophenol. J. Colloid Interface Sci. 2002, 254, 402-405.

50. Koga, H.; Kitaoka, T.; Isogai, A. In situ modification of cellulose paper with amino groups for catalytic applications. J. Mater. Chem. 2011, 21, 9356-9361.

(C) 2011 by the authors; licensee MDPI, Basel, Switzerland. This article is an open access article distributed under the terms and conditions of the Creative Commons Attribution license (http://creativecommons.org/licenses/by/3.0/). 